\title{
Investigating the Possible Damages of Earthquakes in Submarine Pipelines in terms of Disaster Management
}

\author{
${ }^{* 1}$ Redvan Ghasemlounia and ${ }^{2}$ Mert Tolon \\ *10000-0003-1796-4562, Department of Civil Engineering, Faculty of Engineering, Istanbul Gedik University, \\ Istanbul, Turkey \\ ${ }^{2}$ 0000-0002-0131-2976, Department of Civil Engineering, Faculty of Engineering, Istanbul Gedik University, \\ Istanbul, Turkey
}

\begin{abstract}
Earthquake is one of the natural disasters that has always been of interest to researchers. It seems to be difficult to deal with an earthquake due to its accidental nature and unpredictability. Today, with the expansion of cities and the growth in their population, concerns about the increase in casualties and damages caused by the earthquake have increased. Post-earthquake management is highly dependent on predicting the amount and type of damage in any type of structure. Among these structures, little attention has been paid to infrastructures, including underground and submarine pipelines. Given the importance of these structures, research on the impact of earthquakes on these structures and their forms of damages is essential. It is also very important to predict the disaster management plan of the water supply, sewer, oil, and gas pipeline networks due to the earthquake threat. As it is known, the comprehensive approach to disaster management includes prevention (mitigation), preparedness, response, and recovery stages. This study focuses on investigating possible damages in submarine pipelines after an earthquake and study on mentioned disaster management stages and provides an overview of the effects of possible earthquakes on submarine pipelines.
\end{abstract}

Key words: Submarine pipelines; Earthquake; Disaster management; Risk reduction; Pipe failure

\section{Introduction}

With the development of trade, the transport of fluids from one place to another (from one city to another, from one country to another, or from continent to continent) has expanded to meet the needs of societies. Some fluids such as water, oil, natural gas, etc. must be transported in large volumes over long distances. The history of the construction of the submarine pipeline dates back to after World War II. On November 14, 1947, the Kerr-McGee Company, with the help of Brown \& Ruth, completed the construction of the first offshore oil rig, marking the day as the birth of the modern offshore industry (Barnes and McCaslin, 1948).

The pipeline, which is used for transport of any fluid (liquids and gases) from a point to other, is a fixed capital with relatively high underlying costs. The life of these structures, which depends on many factors such as the type of pipe, the type of fluid, operational and environmental conditions, etc., is between 35 to 50 years (Andreikiv, 2012). Pipelines, which are mostly used buried in soil or water, have always faced numerous maintenance problems such as breakage,

\footnotetext{
* Corresponding author: Address: Department of Civil Engineering, Faculty of Engineering, Istanbul Gedik University, Istanbul, Turkey. E-mail address: redvan.ghasemlounia@gedik.edu.tr, Phone: +904445438-1226
} 
destruction, cracking, corrosion or explosion, all of which reduce the useful life expected for the pipeline. There are several reasons that can lead to the damages and destructions of the pipeline, the most important of which are:

- Improper design without considering the increased load due to land changes,

- Poor or inaccurate construction and installation management,

- Use of low quality and non-standard materials,

- Exhaustion of materials used in the manufacture of pipes.

Although pipelines are one of the safest and most economical ways to transport petroleum and gas products, in the event of an accident caused by any of the mentioned reasons, it can have irreparable life losses, economic crises, and environmental damage. Natural disasters, as one of the main reasons for damage in these type structures, are not predictable events and could be divided into two categories, including weather and non-weather disasters. Both weather and nonweather reported disasters are prepared and categorized for years between 1970 and 2019 and presented as Figure 1. From this figure, it is obvious that the earthquake is one of the natural disasters that is mostly occurred during the year around the world (EMDAT (2020): OFDA/CRED international disaster database).

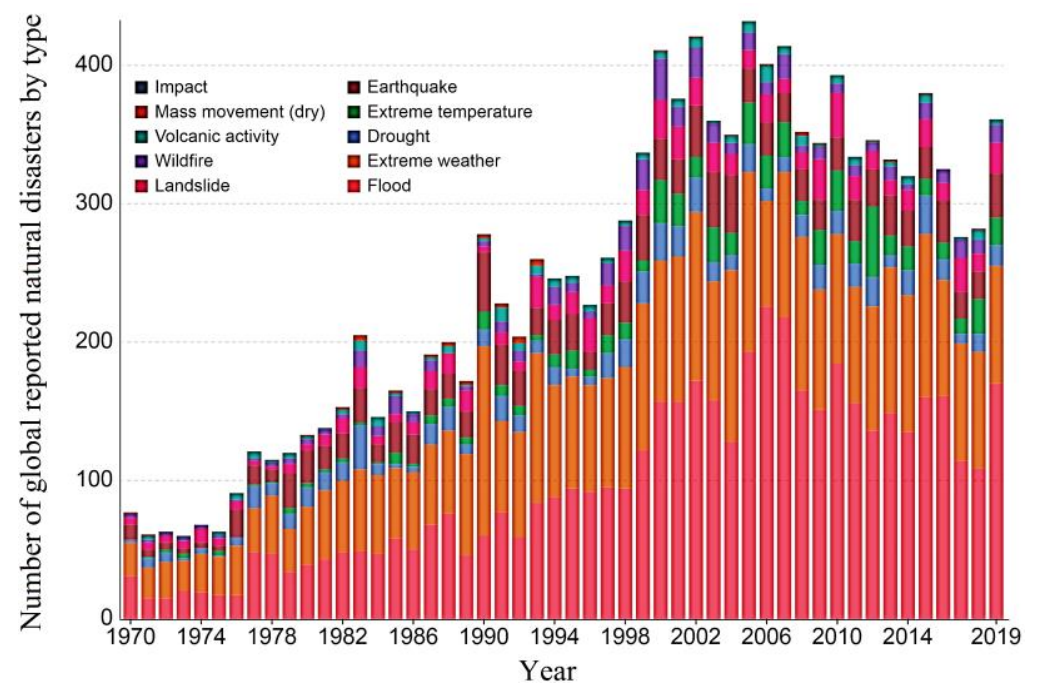

Figure 1: Reported disasters for the period of 1970 to 2019.

Earthquake is a phenomenon that, despite technological advances in recent decades, still causes serious damages to communities and structures. According to statistics provided by the Kerry Institute, the number of the world's significant earthquakes has risen sharply in recent years. Of course, the criteria for classifying the earthquakes as the significant, which is presented in Figure 2, are criteria such as deaths, moderate damage ( $\$ 1$ million or more), magnitude 7.5 or greater, Modified Mercalli Intensity (MMI) X or greater, or generated a tsunami (National Geophysical Data Center of the NOAA). 


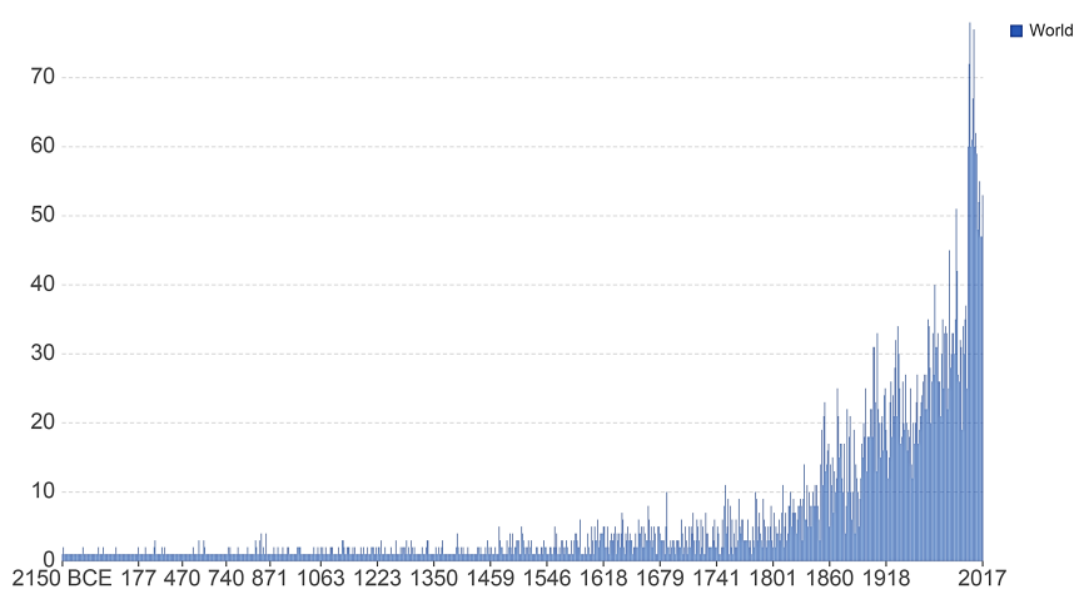

Figure 2: Long history of known earthquakes classified by the National Geophysical Data Center (NGDC) of the NOAA as significant earthquakes

Based on the statistics, the earthquake is led to many life losses and economic losses now and then in the world (Manshoori, 2011). Due to the importance of vital arteries and especially submarine pipelines, the impact of earthquakes on these structures should be investigated, and necessary measures should be taken to reduce damage, which results in economic and life losses, to these critical structures.

\section{Method and Material}

In this study, the impact of the earthquake on submarine pipelines and the parameters affecting these underwater structures during an earthquake will be investigated. Identifying and studying on these parameters will significantly help to control the disaster and reduce its effects. The meaning and definition of disaster are important. Disaster is a dangerous event that has caused major human and economic losses and damages, which requires the necessary response from relief organizations. Disaster management generally consists of three phases: pre-disaster phase, disaster phase, and post-disaster phase.

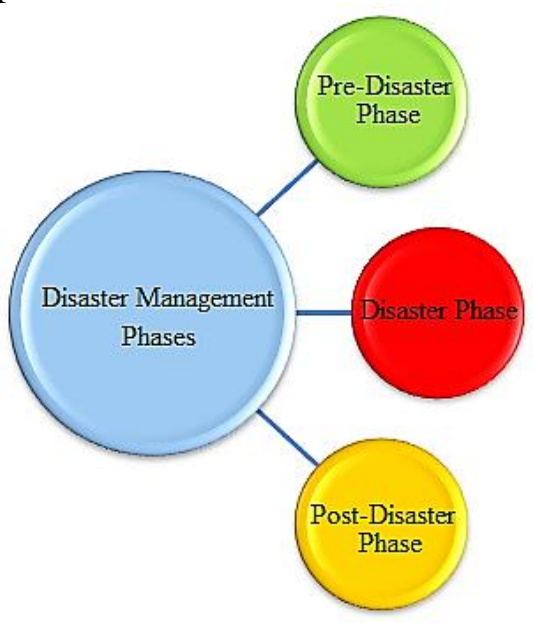

Figure 3: Disaster management phases 
The disaster management cycle has four steps (Kimberly, 2003). Two steps of the disaster management cycle are for before disaster, which named as Pre-disaster phase, including mitigation and preparedness stages and two of its stages, are for during the occurrence of disaster (Disaster Phase) and after that (Post-Disaster Phase), which named as response and recovery steps, respectively. These stages of the disaster management cycle are presented in Figure 4.

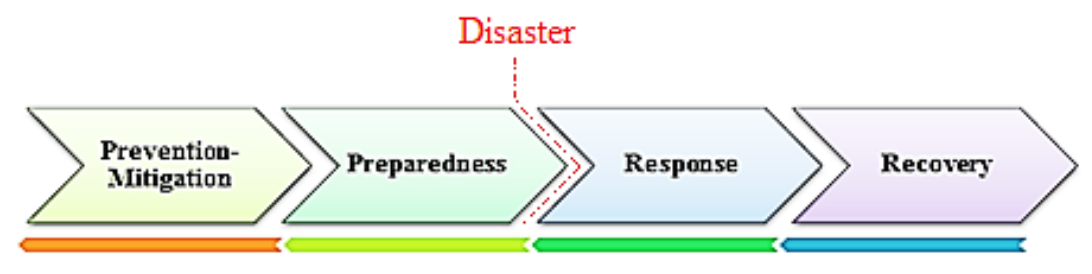

Figure 4: The Disaster management cycle

To reduce the effects of a disaster, all stages of this cycle should be considered before the event occurs. In this paper, the effective parameters of the effects of possible earthquakes on submarine pipelines for each of the mentioned cycle stages are investigated and identified. Therefore, after identifying the mentioned parameters, it could be possible to take appropriate measures to reduce the damages and defects of these structures by conducting scientific research for each of the mentioned parameters numerically and especially experimentally.

\subsection{Prevention Stage (Mitigation)}

The first step in disaster management is prevention. The main goal of this stage is to minimize the effects of possible disasters. Preparation and formulation of the necessary rules and regulations to ensure adequate resistance of new constructed submarine pipelines to any disaster caused by an unexpected event, as well as the necessary measures to strengthen existing submarine pipelines, should be done at this stage. In this paper, this section identifies the types of submarine pipelines, different sections and components of these pipelines, the factors affecting submarine pipelines, available risks in these pipelines, and possible damage due to an event, etc. The importance of this section is that by recognizing each of the mentioned cases, it is possible to prevent the occurrence of risks or provide solutions to reduce these damages. Totally, prevention, in any matter requires sufficient knowledge of the parameters affecting it. These parameters have an important effect on the occurrence of the event as well as on the severity of the crisis. In this stage of the disaster management cycle, as the first step, determining these parameters is essential. From Figure 5, the main causes for failure in pipelines could be divided into three major categories, including structural, environmental, and additional factors. Some of the important causes of failure are explained.

Impact and corrosion are important failure reasons in submarine pipelines, according to Table 1, with a high percentage of equal to $30 \%$ and $26 \%$, respectively (PARLOC, 2001). Most of the items mentioned in this table can be the cause of destruction in these structures due to the seismic forces. Based on Figure 5 and Table 1, the structural and environmental factors, as two major reasons of failure in submarine pipelines, will discussed. 


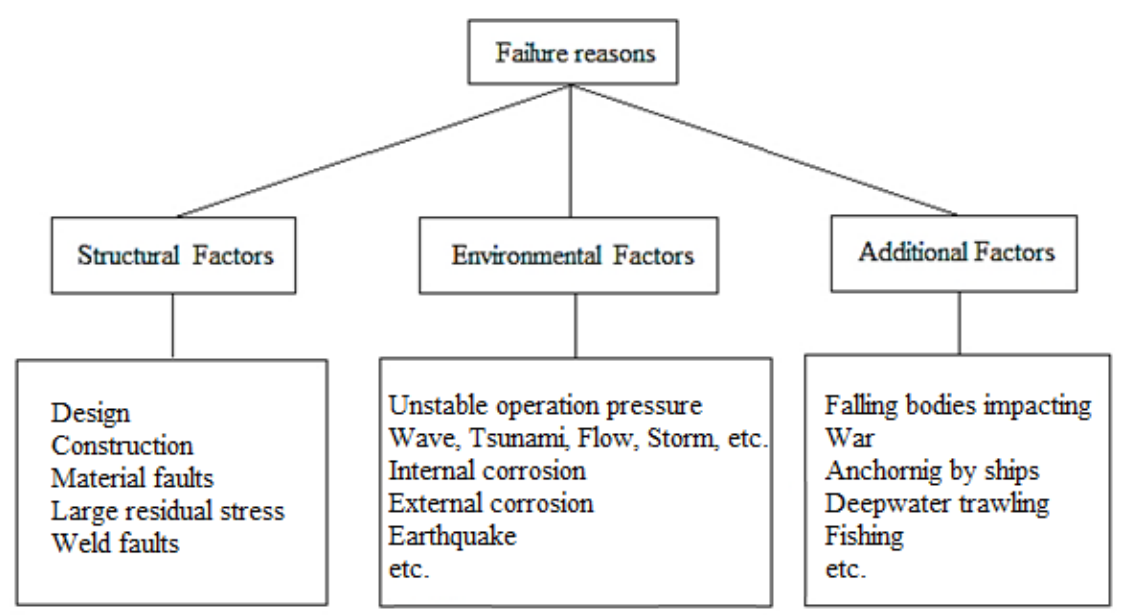

Figure 5: Failure reasons in submarine pipelines (Dongfeng et al., 2015)

Table 1: Submarine pipeline failures and percentages (PARLOC, 2001).

\begin{tabular}{ccc}
\hline Rank & Cause & Percentage \\
\hline $\mathbf{1}$ & Impact & $30 \%$ \\
$\mathbf{2}$ & Corrosion & $26 \%$ \\
$\mathbf{3}$ & Anchor & $21 \%$ \\
$\mathbf{4}$ & Structural & $7 \%$ \\
$\mathbf{5}$ & Material & $6 \%$ \\
$\mathbf{6}$ & Natural & $5 \%$ \\
$\mathbf{7}$ & Hazards & $1 \%$ \\
$\mathbf{8}$ & Maintenance & $1 \%$ \\
$\mathbf{9}$ & Human error & $1 \%$ \\
$\mathbf{1 0}$ & Operational & $1 \%$ \\
$\mathbf{1 1}$ & problems & $1 \%$ \\
\hline
\end{tabular}

\subsubsection{Structural Factors:}

One of the factors that may lead to damage in pipelines and cause economic losses and even loss of life is the lack of proper implementation of these pipelines during the construction period. As a result, the selection of qualified companies with a history of implementation of these structures is very important. Also, continuous and accurate monitoring of the implementation of this type of structures by relevant organizations has a significant impact on their correct and principled implementation. In general, submarine pipelines are installed in different methods. These installing methods are divided into three forms, including reel barge method, pull and tow method, and lay barge method. Since the pipes in these methods are welded on land and then transported to the desired location for installation, and according to the nature of their installation method, some tension or pressure is applied to the pipes during installation. Therefore, if the labor force does not have the necessary skills and expertise, the pipes will be damaged during the installation of these structures, especially from the welds. For example, in O-lay method, due to 
the low operating costs, the possibility of laying of pipes from shallow to depths of thousands of meters, and its high piping speed, this method is significant and popular. The main difference between this method and other current conventional methods is that the welding of pipes and welding tests is done on land and at a short distance from the dock, and after coating, the pipeline is transferred to the desired location in a large flat spiral (Buijvoets, 2011). This method is shown in Figure 6.

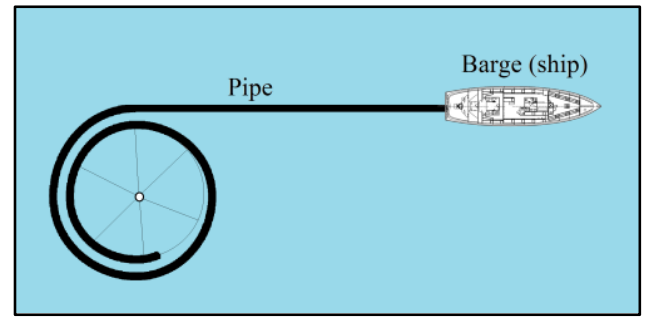

Figure 6: O-lay method

In addition to the following mentioned subjects, in the old piping methods, the pipe was thrown into the sea immediately after welding, which caused the formation and growth of cracks due to fatigue. This will cause weakness at the junctions of the two pipes, and in the event of an almost strong earthquake, will cause damages in the pipeline. In the mentioned methods, this problem is solved. Another important factor in the stability of these structures in facing a strong earthquake is the elements used to stabilize these structures underwater. Therefore, the types and material of the elements and the used method for stabilizing pipes are important factors. On the other hand, choosing the pipe and support materials that are suitable for the environment and using the right materials with high quality in pipeline projects also can help to increase the life of these structures and reduce the probability of damage occurrence in them facing with an earthquake. Concrete and steel, as the most common traditional materials used in the construction of pipelines, are strongly influenced by corrosive environmental factors in the soil or water and are be subject to destruction or corrosion, resulting in major defects in the pipes. The bed, which the pipes will be laid on it, is the other effective parameter in the stability of pipelines. Bed material in submarine pipelines has one of the following situations, presented in Figure 7, based on the type of seabed material.

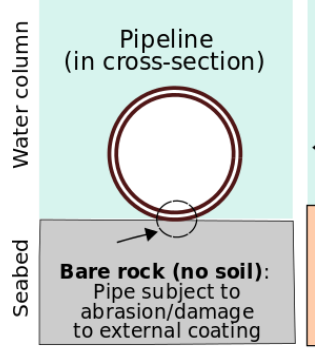

(1)

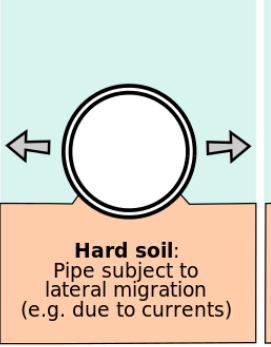

(2)

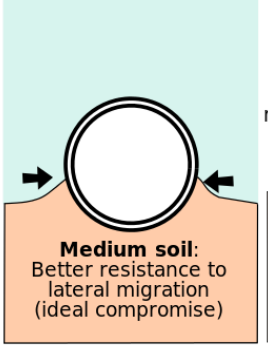

(3) Types of seabed

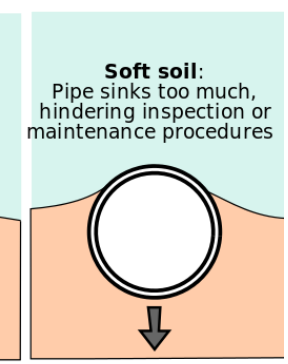

(4)

Figure 7: Type of seabed material (Wikipedia, 2020)

According to Figure 7, about the sea bed soil type, if the seabed is composed of soft soil, the pipe will sink to the sea bed until the soil reactions reach the balance with the downward forces. On 
the other hand, laying of pipes on a bare rock (soilless bed) is led to the increasing of the risk of the damage and failure in the pipeline by waves and bed movements that occurred by earthquakes. Of course, this problem can be solved to a large extent if the pipes are fixed with suitable supports, vertical restraints, and horizontal (lateral) restraints with sufficient distances. Vertical restraint is for controlling vertical displacements, and horizontal restraint is provided to control the lateral displacement (Parish, 2015). Therefore, according to the given figure, the type, material, thickness, and diameter of the selected pipe should be well adapted to the environment and be able to withstand the forces coming from the environment. On the other hand, in the busy routes of ships, in order to prevent the collision of ships and also to prevent the collision of theses ships' anchors, appropriate depth and necessary arrangements should be considered for these lines. In particular, after an earthquake, the pipes may separate from some of their connection points to the bed ground, and the vertical buckling occurs. Especially after the earthquakes with a high magnitude, pipelines should be checked for these kinds of failures for preventing further failures. It will be done in the response and recovery steps of the disaster management cycle.

\subsubsection{Environmental Factors}

Deformation and movements caused by waves and currents could affect the pipelines. Then, if these structures are not designed correctly, the risks of damage in the case of natural events, like earthquakes and Tsunami, will be very high. Therefore, the hydrodynamic stability must be provided. Most likely, the possibility of occurrence of longitudinal deformations and pipeline expansion caused by temperature and pressure changes is high. So, this subject has importance in designing pipelines. Other environmental factors such as water salinity, the water temperature at the desired depth, and in different seasons, in choosing the type of pipes and supports used in the lines, must be considered in the design and implementation of these offshore structures. The condition of the coating or isolation of this type of structures pipes is desirable because in steel pipes, the failure of the coating causes corrosion in the pipes due to being in contact with water and the highly corrosive properties of these waters, and as a result, it will led to the creation of the critical cross-section.

\subsubsection{Natural disasters}

Unexpected natural disasters are one of the most important causes of the destruction or failure of submarine pipelines. These natural disasters mostly include seabed movements caused by highmagnitude earthquakes, and sometimes tsunamis and the formation of strong waves as a result of these earthquakes. Therefore, the stability analysis of pipes at sea bed is performed to ensure the stability of the pipeline when exposed to waves, current forces, and other internal and external loads (such as bending loads in curved sections of the pipeline). Particularly in earthquake-prone areas, the potential forces caused by earthquakes, as mentioned, should also be considered. Also, the behavior of the designed pipelines during an earthquake should be investigated. Depending on whether submarine pipelines are buried or not, as well as whether they are in the sea or on land, the construction method of these pipelines and the types of connections and supports are different. Therefore, the method of execution, the type of connections, and the type of pipeline could be important in the amount of damage during a natural disaster such as an earthquake. Several researches have been done by various researchers in this field. Although these studies are mostly computational and very few of them have been performed in the laboratory, the results 
have been very helpful in the prediction of the reaction of the pipelines in different conditions of these unexpected events. Some of these researches are presented in the table below. Selected parameters by researches for their studies are marked in this table. As it is obvious from the given table, the number of numerical studies is significantly more than the experimental researches. It is also clear that there is no study available which covers all the parameters that occurred during and after an unexpected natural event such as earthquakes. Therefore, in the case of disaster management, it is an important subject to do a study for all probable conditions of pipeline and earthquake.

Table 2: Numerical and experimental studies on submarine pipelines

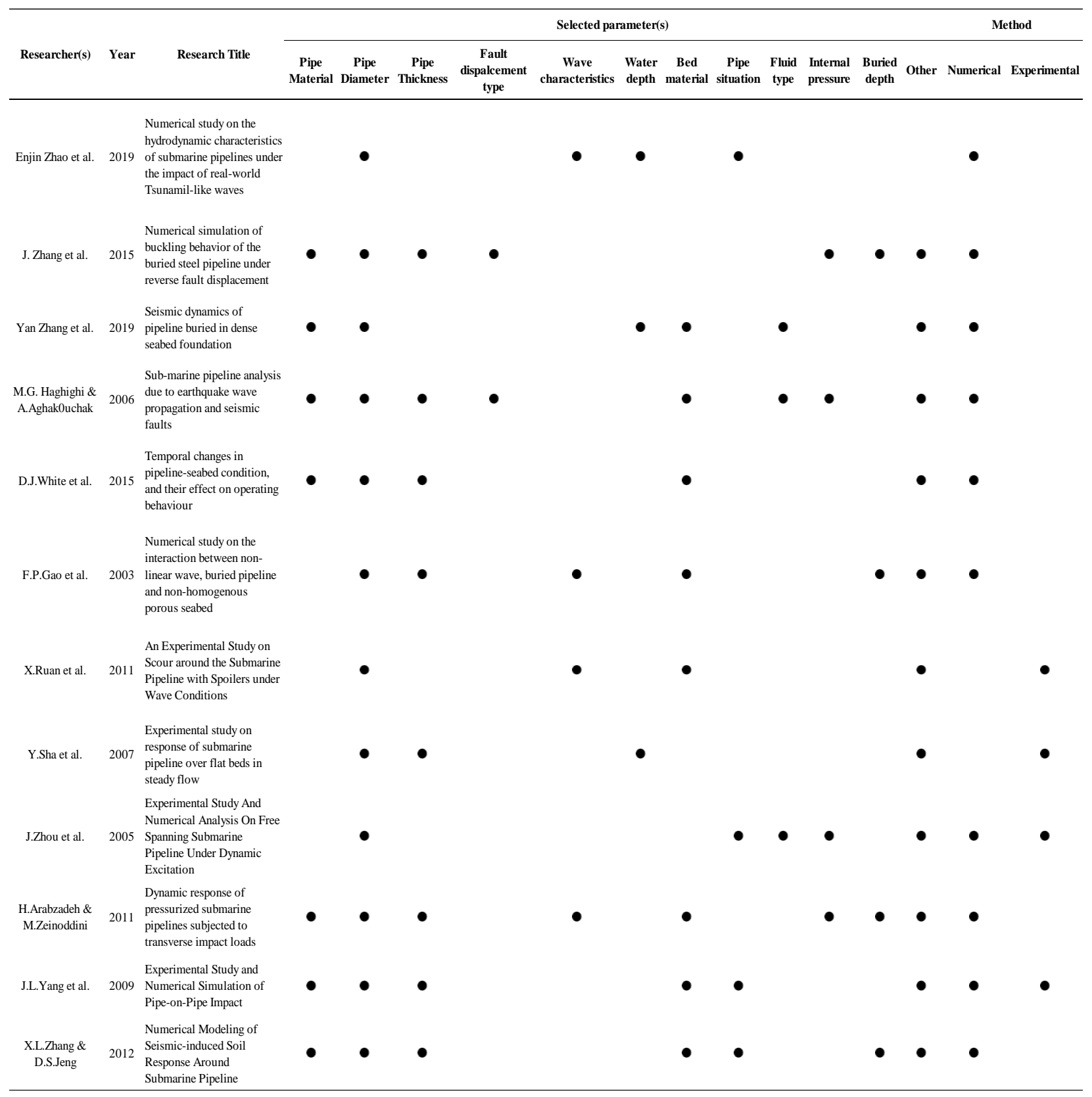




\subsection{Preparedness Stage:}

Given that any of the problems can lead to a disaster that is mentioned follow, the reconstruction and repair of pipelines on a large scale and in the shortest possible time are of great economic, technical and environmental importance. In the past, traditional methods were used to repair and rebuild pipelines. These techniques are still used today and include drilling and excavating to access the damaged pipe and then replacing it or applying metal sleeves to the damaged parts.

The use of fiber-reinforced polymer composite technology to repair, rebuild, and strengthen damaged pipelines is one of the most up-to-date methods in the world. These materials have low weight and high specific strength and have high corrosion resistance for long periods of time, which increases their durability and efficiency, thus their high reliability. These periodic inspections and repairs of submarine pipelines are a way to prepare for a deal with potential crises and decreasing the effects of the available risks. Therefore, periodic inspection and repairing of damaged and defective parts of pipelines are necessary to prevent or reduce the effect of a crisis when a natural event occurs. Using new technologies and materials in repairing or replacing damaged parts in submarine pipelines is also important. One of the things that must be taken before an occurrence of an event, like an earthquake, is to prepare a plan for such events. Therefore, regular inspections, diagnosis, and elimination of defects and weaknesses in these pipelines are important, so these actions should be done at this stage. The dividing of duties and responsibilities is essential for times that the crisis happened. It means what is the duty and responsibility of any organization and even a person at the time of the occurrence of an event. Examining similar cases that have occurred in other countries, if any, and benefiting from the experiences of other countries and individuals in this field also could be very effective and useful in preparing for disasters.

\subsection{Response Stage:}

This stage of disaster management is to take action and respond quickly to the occurrence of the disaster and is done in order to save lives and property, continue to provide services, and prevent the spread of damages and losses caused by the disaster. Necessary measures for submarine pipelines after an earthquake include control of pipelines to identify areas of fluid leakage in these structures, action of responsible persons to eliminate defects, the establishment of vital arteries, and other related emergency services. A quick response of responsible individuals and organizations should be made according to the pre-written plan for disaster situations. The concept of disaster management will be clearly seen at this stage. Also, the training provided to the responsible people and the use of equipment and facilities with the latest technologies in the world will help a lot in controlling the situation and returning to normal in the shortest possible time and with the least damage and losses at this stage. Another important factor that shows its own influence in all stages of crisis management will be the use of experiences related to similar cases, which should have been reviewed in advance before the occurrence of the disaster. In general, this stage can be a crucial stage in disaster management.

\subsection{Recovery Stage:}

The recovery stage includes all necessary measures after the disaster, such as earthquakes, which is done to restore the conditions of the affected areas to normal conditions. Besides, it should also be noted that the estimation of damages and losses after the occurrence of a disaster such as an 
earthquake could help to manage the disaster. At this stage, the contaminants caused by the leakage of fluids inside the submarine pipeline should be cleaned, and the contaminants should not be allowed to spread too much.

\section{Results and Discussion:}

By reviewing the researches and the mentioned cases, the necessary measures taken to reduce the life and economic losses following the possible earthquake in the submarine pipelines for the different phases and stages of disaster management can be presented in Table 3.

Table 3: Disaster management stages for submarine pipelines for a possible earthquake

\begin{tabular}{|c|c|c|c|}
\hline \multirow{2}{*}{$\begin{array}{c}\text { Disaster Management } \\
\text { Phases } \\
\text { Disaster Management } \\
\text { Stage }\end{array}$} & Pre-Earthquake Phase & \multirow{2}{*}{$\begin{array}{c}\text { During Earthquake Phase } \\
\text { Response }\end{array}$} & \multirow[t]{2}{*}{ Post-Earthquake Phase } \\
\hline & Preparedness & & \\
\hline & Education & $\begin{array}{l}\text { Quick formation of the crisis } \\
\text { committee meeting }\end{array}$ & $\begin{array}{c}\text { Continue to identify earthquake } \\
\text { damages }\end{array}$ \\
\hline & Research & $\begin{array}{l}\text { Deploying responsible people in } \\
\text { predetermined situations }\end{array}$ & $\begin{array}{l}\text { Checking of necessary actions to } \\
\text { resuming the provision of pipeline } \\
\text { services }\end{array}$ \\
\hline & $\begin{array}{l}\text { Identification of parameters affecting } \\
\text { pipelines during an earthquakes }\end{array}$ & $\begin{array}{l}\text { Closing pipeline valves } \\
\text { (If available) }\end{array}$ & $\begin{array}{c}\text { Replacement of damaged and } \\
\text { damaged pipes }\end{array}$ \\
\hline & $\begin{array}{l}\text { Investigate the impact of each of the } \\
\text { parameters affecting pipelines }\end{array}$ & $\begin{array}{l}\text { Identification and localization of } \\
\text { sites of damaged pipes }\end{array}$ & Repairing of welded joints \\
\hline & $\begin{array}{l}\text { Prioritizing parameters affecting } \\
\text { pipelines in an earthqauke }\end{array}$ & Leak detection & $\begin{array}{l}\text { Providing reports of damages for } \\
\text { future scientific studies }\end{array}$ \\
\hline & Identifying weaknesses in pipelines & $\begin{array}{l}\text { Use the opinions of experienced } \\
\text { people in this field }\end{array}$ & Back to normal \\
\hline & Improving the quality of used materials & & $\begin{array}{l}\text { Prevention of the spread too much } \\
\text { contaminants caused by the leakage }\end{array}$ \\
\hline & $\begin{array}{l}\text { Supervising the correct and principled } \\
\text { implementation of pipelines }\end{array}$ & & $\begin{array}{c}\text { Cleaning the contaminants caused } \\
\text { by the leakage }\end{array}$ \\
\hline & $\begin{array}{l}\text { Proper design and proper selection of } \\
\text { specifications of pipes and fittings }\end{array}$ & & \\
\hline & Inspection and controling of pipelines & & \\
\hline & Fixing the available defects in pipelines & & \\
\hline & $\begin{array}{l}\text { Planning and division of responsibilities } \\
\text { for disaster situations (earthquake) }\end{array}$ & & \\
\hline & $\begin{array}{l}\text { Investigating similar incidents and using } \\
\text { of the experiences of others }\end{array}$ & & \\
\hline & $\begin{array}{l}\text { Providing equipment with the latest } \\
\text { technologies in the world to better deal } \\
\text { with the earthquake disaster }\end{array}$ & & \\
\hline
\end{tabular}




\section{Conclusion}

Since the probability of occurrence of natural and unnatural disasters high in any society, it is necessary to plan ahead to reduce their effects before they occur. Disaster management is done in three phases as pre-disaster, disaster, and post-disaster phases. The disaster management cycle has four stages, including prevention or mitigation, preparedness, response, and recovery stages. By reviewing the studies that have been done in the case of the effect of an earthquake on submarine pipelines in recent years, the disaster, its levels, and management have been studied in this paper. Important parameters affecting underwater pipelines during the earthquake were identified. Necessary measures were proposed to reduce possible damages to these underwater structures during an earthquake. Reviewing the researches conducted in this field, it was observed that the study on the parameters affecting this type of pipelines during an earthquake was mostly in the form of numerical models, and experimental methods were rarely used. Therefore, conducting an experimental study considering most of the parameters affecting pipelines in the event of an earthquake seems necessary.

\section{Acknowledgements}

This work was a part of the Scientific Research Projects, which was supported by the Scientific Research Projects Coordination Unit of Istanbul Gedik University. We extend our sincerest thanks and gratitude to Istanbul Gedik University.

\section{References}

Andreikiv, O. \& Hembara, Oksana \& Tsyrul'nyk, O. \& Nyrkova, L.. (2012). Evaluation of the residual lifetime of a section of a main gas pipeline after long-term operation. Materials Science. 48. 10.1007/s11003-012-9497-7.

Arabzadeh, Hamid \& Zeinoddini, M.. (2011). Dynamic Response of Pressurized Submarine Pipelines Subjected To Transverse Impact Loads. Procedia Engineering. 14. 648-655. 10.1016/j.proeng.2011.07.082.

Barnes, K.B., and McCaslin, L.S. Jr. 1948. Gulf of Mexico Discovery. Oil \& Gas J 47 (March 18): 96.

Buijvoets, J., (2011 ). Offshore O-lay pipe laying. Pipeline Technology Conference, Hannover.

Enjin Zhao, Ke Qu, Lin Mu, Simon Kraatz and Bing Shi. (2019). Numerical Study on the Hydrodynamic Characteristics of Submarine Pipelines under the Impact of Real-World TsunamiLike Waves, Water 2019, 11(2), 221; https://doi.org/10.3390/w11020221.

Gao, F.P., Jeng, D.S., Sekiguchi, H. (2003). Numerical study on the interaction between nonlinear wave, buried pipeline and non-homogenous porous seabed, Computers and Geotechnics, Volume 30, Issue 6, 2003, Pages 535-547, ISSN 0266-352X, https://doi.org/10.1016/S0266$352 \mathrm{X}(03) 00053-3$. 
Kimberly A. (2003), "Disaster Preparedness in Virginia Hospital Center-Arlington after Sept 11, 2001". Disaster Management and Response 1(3): pp. 80-86.

MacDonal M., "PARLOC 2001". The update of loss of containment data for offshore pipeline", Prepared for The Health and Safety Executive, The UK Offshore Operators Association and The Institute of Petroleum, 12 June 2003.

Manshoori, M. R., (2011). Evaluation of Seismic Vulnerability and Failure Modes for Pipelines. Procedia Engineering 14 (2011) 3042-3049. doi:10.1016/j.proeng.2011.07.383

Mao, Dongfeng \& Chu, Gui \& Yang, Lei \& Li, Zhigang. (2015). Deepwater Pipeline Damage and Research on Countermeasure. Aquatic Procedia. 3. 10.1016/j.aqpro.2015.02.209.

Parish, Y., (2015). Investigating the effect of earthquake on urban water distribution networks. International Conference of Research in Science and Technology, Kualalumpur, Malaysia.

Ruan, X., Shi, B., Yang, L., and Zhang, Z. (2011). "An experimental study on scour around the submarine pipeline with spoilers under wave conditions," 2011 International Conference on Remote Sensing, Environment and Transportation Engineering, Nanjing, 2011, pp. 2891-2895, doi: 10.1109/RSETE.2011.5964918.

Sha Y., Wang Y.X., Wang G.Y., Li G.W., Chen Z.J. (2007) Experimental Study on Response of Submarine Pipeline over Flat Beds in Steady Flow. In: Zhuang F.G., Li J.C. (eds) New Trends in Fluid Mechanics Research. Springer, Berlin, Heidelberg. https://doi.org/10.1007/978-3-54075995-9_104.

Thou, J. \& Li, Xin \& Dong, R.. (2005). Experimental study and numerical analysis on free spanning submarine pipeline under dynamic excitation. Proceedings of the International Offshore and Polar Engineering Conference. 2005. 135-140.

Yang, J. L., Lu, G. Y., Yu, T. X., \& Reid, S. R. (2009). Experimental study and numerical simulation of pipe-on-pipe impact. International Journal of Impact Engineering, 36(10-11), 12591268. https://doi.org/10.1016/j.ijimpeng.2009.05.001.

Zhang, J., Liang, Z., Han, C. J., and Zhang, H. (2015). Numerical simulation of buckling behavior of the buried steel pipeline under reverse fault displacement. Mech. Sci., 6, 203-210, 2015. www.mech-sci.net/6/203/2015/doi:10.5194/ms-6-203-2015.

Zhang, X.L., Jeng, D.S. (2012). Numerical Modeling of Seismic-induced Soil Response around Submarine Pipeline. The Open Civil Engineering Journal, 2012, 6, 98-106.

http://ngdc.noaa.gov/, Long history of known earthquakes classified by the National Geophysical Data Center (NGDC) of the NOAA as significant earthquakes, Accessed: August 2020.

https://en.wikipedia.org/wiki/File:Submarine_Pipeline_vs_seabed.svg, Accessed: Auguest 2020.

https://ourworldindata.org/ofdacred-international-disaster-data, Accessed: August 2020. 